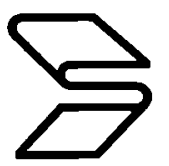




\section{Dortmunder Beiträge zur Zeitungsforschung}

\section{Band 58}

Herausgegeben von Hans Bohrmann und Gabriele Toepser-Ziegert

Institut für Zeitungsforschung der Stadt Dortmund 


\title{
Zeitungsdruck
}

\section{Die Entwicklung der Technik vom 17. zum 20. Jahrhundert}

\author{
Mit Beiträgen von \\ Martin Welke und Boris Fuchs
}

K·G·Saur München 2000 
Die Deutsche Bibliothek - CIP-Einheitsaufnahme

\section{Zeitungsdruck :}

die Entwicklung der Technik vom 17. zum 20. Jahrhundert /

mit Beitr. von Martin Welke und Boris Fuchs. - München : Saur, 2000

(Dortmunder Beiträge zur Zeitungsforschung ; Bd. 58)

ISBN 3-598-21321-2

(⿻)

Gedruckt auf säurefreiem Papier

(c) 2000 by K. G. Saur Verlag GmbH \& Co. KG, München

Part of Reed Elsevier

Printed in the Federal Republic of Germany

Alle Rechte vorbehalten / All Rights Strictly Reserved

Diese Werk - oder Teile daraus -

darf nicht vervielfältigt, in Datenbanken gespeichert oder in irgendeiner Form - elektronisch, photomechanisch, auf Tonträger oder sonstwie - übertragen werden ohne die schriftliche Genehmigung des Verlags.

Druck/Binden: Strauss Offsetdruck $\mathrm{GmbH}$, Mörlenbach

ISBN 3-598-21321-2 